\title{
A Visibilidade do INVISÍvel EM CoNTOS Transantropológicos, de Atena Beauvoir*
}

\author{
Visibility of the invisible in Contos \\ Transantropológicos by Athena Beauvoir
}

\author{
Adauto Locatelli Taufer ${ }^{1}$ \\ ${ }^{1}$ Universidade Federal do Rio Grande do Sul, Colégio de Aplicação. Porto Alegre, RS, Brasil. \\ E-mail: adautotaufer@gmail.com
}

EDITOR-CHEFE:

Gerson Roberto Neumann

EDITOR EXECUTIVO:

Regina Zilberman

SUBMETIDO: 30.04 .2021

ACEITO: 15.06 .2021

COMO CITAR:

TAUFER, Adauto

Locatelli. A visibilidade

do invisível em Contos

Transantropológicos, de Atena

Beauvoir. Revista Brasileira

de Literatura Comparada,

v. 23 , n. 44 , p. $259-264$, set.-

dez., 2021. doi: https://

doi.org/10.1590/2596-

$304 \times 20212344$ alt http:// www.scielo.br/rblc https://revista.abralic.org.br
Nem pederasta, nem mulher, nem homem, nem nada que outros pudessem designar, ele era ele, aquilo, qualquer coisa psíquica e mais acertadamente genética, estético e psicologicamente fantástico!

Cassandra Rios, Georgette distintas noura $\mathrm{XX}$ abriu espaço para que textos à margem do cânone fossem postos em evidência, assegurando a essas vozes marginalizadas a possibilidade de serem representadas e, mais que isso, ouvidas. Refiro-me aqui, especificamente, aos estudos dos movimentos feministas, gays, lésbicos e negros. Parece-me que, na tradição literária, textos que se distanciassem do falocentrismo, do heterossexismo e da hegemonia branca eram ignorados.

Embora os estudos gays e lésbicos, por exemplo, tenham conquistado alguma representatividade, textos que problematizam a sexualidade e as questões de gênero ainda hoje são relegados ao submundo da marginalidade, à dita subliteratura ou literatura de "menor" valor. Fato é que esses estudos por se oporem à hegemonia heteronormativa continuam a se constituir como uma ameaça à afirmação das identidades binárias, ou seja, aos conceitos sócio-histórico-biológicos das definições de homem e de mulher, enquanto portadores dos respectivos órgãos genitais masculino e feminino. Nesse sentido, o indivíduo transgênero é aquele que não se identifica com o sexo com o qual nasceu. E isso não significa que ele seja, necessariamente, transexual, uma vez que pode, simplesmente, não se identificar com o

* Resenha de: BEAUVOIR, Atena. Contos transantropológicos. Porto Alegre: Taverna, 2018. 
binarismo (noção de pertencimento a um dado sexo). E isso, também, não implica a necessidade de adequação do corpo com o qual se identifica, realizando tratamentos hormonais ou cirurgias de redesignação sexual, por exemplo. Considerando apenas essas definições de homem e de mulher, portanto, é impossível assegurar que identidades de gênero distanciadas da categorização binária - homens e mulheres trans ${ }^{1}$ - se sintam representadas, ficando banidas à invisibilidade, tanto na esfera social quanto no âmbito literário. Afinal, ter pênis não significa, obrigatória e necessariamente, identificar-se com o gênero masculino. Conforme Butler (2017), a respeito desse equívoco identitário:

Os homens "têm" o Falo mas nunca o "são", no sentido de que o pênis não é equivalente à Lei, e nunca poderá simbolizá-la plenamente. Assim, verifica-se a impossibilidade necessária ou pressuposta de todo esforço para ocupar a posição de "ter" o Falo, com a consequência de que ambas as posições, a de "ter" ou a de "ser", devem ser entendidas nos termos de Lacan, como fracassos cômicos, todavia obrigados a articular e encenar essas impossibilidades repetidas. (BUTLER, 2017, p. 88-89, grifos do autor)

Na esfera literária, a partir 1985, com o fim da ditadura militar e com a segunda redemocratização do Brasil, ${ }^{2}$ surgem editoras direcionadas a publicações gays - a exemplo da Editora GLS Publicações cujos protagonistas dos romances são personagens homossexuais, lésbicas e, embora em menor número, personagens trans e travestis. A título de exemplificação, o romance Nicola - um romance transgênero, de Danilo Angrimani (1999), narrativa pioneira por contemplar a naturalidade dos gêneros, contém um personagem trans como protagonista - o professor universitário circunspecto, casado e pai de família, que esconde uma identidade oculta, pois, ao se olhar no espelho, depara-se com uma mulher libertina que aguarda a coragem do sério professor chefe de família para manifestar sua condição de mulher trans. ${ }^{3}$

Não se pode ignorar, entretanto, o traço recorrente da marginalidade que caracteriza as personagens trans. Geralmente, quando a personagem travesti aparece representada na literatura brasileira contemporânea, o abandono familiar, o desajustamento social, a exploração sexual, a morte, a precariedade econômica, a solidão e a violência, entre outros, são aspectos que norteiam a composição dessa personagem. Essa literatura de minorias (transgênero) produzida para a maioria (cisgênero) desvela, revela e denuncia a subalternidade dessas personagens na sociedade, na literatura brasileira. Trata-se, aqui, de uma literatura de denúncia, de existência e de resistência contra a transfobia e contra o preconceito de gênero sociocultural e sócio-histórico solidamente alicerçados na sociedade brasileira.

Na esteira dessa atmosfera de resistência, de denúncia e, sobretudo, de existência, Atena Beauvoir ${ }^{4}$ (2018) publica Contos Transantropológicos pela Editora Taverna. A obra contém 31 contos distribuídos ao longo de 165 páginas. São contos de extensão relativamente curta narrados em terceira pessoa (maioria) e em primeira pessoa (apenas quatro contos - "No sofá da existência”, "Disforia”, “Amém” e "A voz da consciência”). A epígrafe do livro, em franco diálogo com Hamlet, de William Shakespeare, já aponta para as questões que serão abordadas sequencialmente nos contos: "Há mais coisas entre um

$1 \mathrm{O}$ vocábulo trans utilizado neste texto relaciona-se às pessoas travestis, transexuais, transgêneras e não binárias.

2 A primeira redemocratização ocorre em 1945 quando Getúlio Vargas foi destituído do poder com o fim do Estado Novo.

3 O comentário a respeito dessa obra foi elaborado a partir da leitura da dissertação de mestrado intitulada De Orlando a Orlanda: performances trans na literatura do século XX, de Marcelo Branquinho Massucatto Resende. Disponível em: https://repositorio.unesp.br/bitstream/ handle/11449/180962/resende_mbm_me_arafcl.pdf?sequence=5\&isAllowed=y. Acesso em: 10 maio 2021.

4 Escritora, poeta, professora e graduanda do Curso de Licenciatura em Filosofia na Universidade Federal de Pelotas (UFPEL). 
pênis e uma vagina, entre o masculino e o feminino, entre o homem e a mulher, do que supõe a nossa vã filosofia" (Atena Beauvoir). A intertextualidade com a peça de Shakespeare deflagra o projeto literário de Beauvoir em Contos Transantropológicos: desconstrução de padrões e de práticas hegemônicas do patriarcado heteronormativo com o propósito de retirar as pessoas trans da indefinição sociossexual, seja na realidade, seja na ficção, atribuindo-lhes um lugar de pertencimento e de reafirmação da identidade trans dentro de uma produção literária de representação.

No prefácio da obra, intitulado "Introdução à Transantropologia”, a autora deixa bastante claro para o leitor que ele não está apenas diante de um "apanhado de histórias com um fundo moral e ético sobre os relacionamentos e o respeito entre os seres humanos”, pois, para além disso, os contos apresentam "um novo olhar para a existência humana, não somente pelo estilo da escrita, de ordem literária e ficcional, ou por suas funções sociais, mas pela própria exposição das vidas de personagens trans" (BEAUVOIR, 2018, p. 11, grifo da autora). E a exposição dessas vidas não é feita de uma autora transgênero para leitores transgênero, pois estes já conhecem muito bem a árdua condição das pessoas trans. Por isso, as vidas das personagens trans em evidência são direcionadas, sobretudo, aos leitores cisgênero, que, ao contrário das pessoas transgênero, não têm suas existências e suas identidades constantemente questionadas porque estão dentro do padrão hegemônico binário. Para desconstruir os conceitos de homem e de mulher biologicamente sedimentados desde sempre, a Transantropologia assume que "não há um modelo humano. Não há verdade de uma unidade humana. Não há destino para a espécie humana senão aquele que ela mesma constrói para si, querendo chamar de natural, comum ou normal" (BEAUVOIR, 2018, p. 12).

Especificamente no que tange aos contos, considerando o limite de extensão deste texto, não vou aqui me deter a tecer comentários e a explanar a temática e o enredo de cada um deles; em vez disso, vou discorrer a respeito de alguns fios que atam as 31 narrativas que corporificam os Contos Transantropológicos, quais sejam: personagens transgênero, muitas vezes, dotadas de uma aparência andrógina (em sua maioria mulheres trans e algumas vezes homens trans) que são massacradas pela violência, tanto física quanto psicológica, sofrida no seio familiar, na escola, no trabalho, na sociedade como um todo. As vidas dessas personagens são constantemente permeadas pelo sofrimento, pelo abandono e, principalmente, pela invisibilidade de sua existência porque não encontram espaços, tampouco meios para existirem dentro de corpos com os quais não se identificam. Restam-lhes, em boa medida, as noites nas ruas quando a cidade está mais escura, à meia luz (e, dessa maneira, as vidas transgênero são menos visíveis, quase invisíveis) e a exploração sexual como meio de sobrevivência, nunca de existência. Suas existências, aliás, não são definidas por si próprias, mas pelas personagens cisgênero que definem os conceitos de homem e de mulher, de masculino e de feminino: "por suas vizinhas, por seus professores, por seus colegas, por sua mãe e por toda a sua família” (BEAUVOIR, 2018, p. 24). Mais que isso: as genitálias das personagens trans não refletem o gênero com o qual elas se identificam.

O questionamento constante a respeito de ser homem e de ser mulher está para muito além de possuir pênis ou vagina, pois, mesmo que de maneira inconsciente, para as personagens trans de Contos Transantropológicos, "Ninguém nasce mulher: torna-se mulher. Nenhum destino biológico, psíquico, econômico define a forma que a fêmea humana assume no seio da sociedade (...)" (BEAUVOIR, 1967, p. 9). Essa famosa frase de Simone de Beauvoir que dá início ao segundo volume do polêmico 
O Segundo Sexo, quando a autora questiona o fato de, em meados do século XX, ainda ser tolhido das mulheres o direito de pensar e de agir de modo distinto ao do homem, ajusta-se tal qual uma luva às personagens trans construídas por Atena Beauvoir. Essa notória máxima da escritora francesa se estende aos homens trans e às mulheres trans que compõem os distintos enredos de Contos Transantropológicos porque indivíduos cisgênero e transgênero tornam-se e se constituem dessa forma ao se identificarem ou não com os corpos que possuem. Tornar-se transgênero é conquistar a possibilidade de existir num mundo que, desde o nascimento, só confere esse direito aos indivíduos cisgênero.

Assim, a tessitura narrativa engendrada por Atena Beauvoir apresenta uma galeria de personagens transgênero que, desde a infância, se definem como menino ou como menina "não porque seu corpo assim indicava, mas porque sua forma de existir assim se fazia” (BEAUVOIR, 2018, p. 40). Por conta dessa condição "desviada do padrão", essas personagens passam por diversas situações de constrangimento, de inexistência e de invisibilidade que, mesmo indiretamente, se convertem em episódios de humilhação, como ilustra o conto "Mulheres e suas próstatas" em que Estela, mulher trans, vai ao urologista para realizar o exame da próstata e vê sua identidade e, consequentemente, sua existência ignoradas pela secretária do médico:

— Ficha número 15!

Ela se levanta num susto. A sala estava quase vazia. Pendurou sua bolsa no ombro, pegou os seus documentos e o guarda-chuva.

- O que seria para a senhora? - questiona a atendente, imaginando que a consulta marcada fosse para um filho ou neto.

— Eu tenho consulta marcada com o Dr. Celson! - ela responde e entrega os documentos.

— Desculpe, senhora, mas o Dr. Celson só atende homens. Ele é urologista! - a voz inocente da atendente se faz ouvir por algumas pessoas que estavam sentadas aguardando atendimento. Todos focaram a atenção em Estela e na sua insistência em querer a consulta com um urologista. (BEAUVOIR, 2018, p. 42)

Esse conto termina após a mulher trans, desprotegida e insegura, desistir de consultar com o Dr. Celson no instante em que Estela recupera seus documentos e agradece à secretária, afirmando ter se enganado. Essa invisibilidade microcósmica dentro do consultório médico, dentro do conjunto de narrativas de Contos Transantropológicos, representa uma espécie de alegoria do macrocosmo social que fecha os olhos para a humanidade transgênero. Talvez, desistir do embate frente a frente seja uma das formas de conviver com o descaso há muito tempo evidenciado por muitas pessoas cisgênero em relação às transgênero. Certamente, não é a melhor escolha! Comolutar, entretanto, quando se tem um exército armado à frente e se está desarmado? E é exatamente o contrário disso que Atena Beauvoir faz: ela luta com as melhores armas que possui - a escrita. Uma escrita que não se deixa silenciar e que toma a palavra como principal aliada para deflagrar o que há muito está submerso no que tange à condição transgênero. A autora de Contos Transantropológicos não permite que seus pares permaneçam invisíveis.

Encaminhando a análise para o final, destaco uma situação emblemática presente no último conto do livro, "Transtopia”, que pode ser estendida ao sentimento de invisibilidade e de negação da condição transgênero presente na maioria das narrativas, ou em todas, compostas por Atena Beauvoir. É o sentimento comum que caracteriza todas essas personagens porque elas são olhadas, mas não são vistas. 
No conto acima referido, há uma acalorada discussão entre a recepcionista do hospital e Milena (mulher trans) que aguarda o nascimento de seu filho. Milena se apresenta como sendo a mãe da criança e isso desencadeia uma série de questionamentos irônicos feitos pela recepcionista, fato que deflagrará uma situação constrangedora porque Milena não se vê reconhecida como uma mulher trans e todas as implicações que essa definição possui:

— Qual seu grau de parentesco com a mãe? - questionou a recepcionista.

— Eu sou a mãe! - respondeu encabulada.

A recepcionista observou Milena por um instante, como se estivesse em frente a um enigma.

— Então o procedimento foi inseminação artificial? Tudo bem, Milena. Nosso hospital é dedicado a todos os tipos de famílias, inclusive as homoparentais - respondeu sorrindo, enquanto mexia em alguns papéis.

— Moça... - Milena interrompeu a recepcionista. - Não foi inseminação artificial.

- Senhora, não estou entendendo. Preciso que essa ficha seja preenchida, mas se não é inseminação artificial, como a senhora seria a mãe? Onde está o pai do bebê? - questionou, demonstrando certa impaciência e ironia.

(...)

— Olha só... - levantou a voz, de forma didática - Não sei qual o preparo que vocês têm nesse hospital. A forma como você está levando o assunto me constrange e me leva a crer que você não sabe o que está fazendo aqui. $\mathrm{O}$ pai da criança está na sala de atendimento, pois sentiu fortes dores. Eu estou esperando faz uma hora, e acho incrível que você, que trabalha aqui, não tenha visto um homem grávido de 8 meses em uma cadeira de rodas passar por esse corredor. Então, antes que você questione com qualquer sandice, eu e ele somos casados e estamos esperando um filho. Eu sou a mãe e ele o pai. Tem mais alguma dúvida?

(...) A recepcionista inquiriu:

- A senhora é transexual?

— Eu sou a mãe da criança. Ele é o pai. Nós somos um casal esperando o nascimento do nosso filho para formarmos a nossa família. Não há nenhuma necessidade de qualquer outra pergunta relativa à mim (sic) ou ao meu marido, senão realizar o seu trabalho. (BEAUVOIR, 2018, p. 163-4)

Após esse episódio constrangedor, o médico de Miguel vem conversar com Milena, tranquilizando-a ao avisar que tudo não havia passado de um susto. Então, o casal volta para casa, seguindo as recomendações médicas de ficarem atentos, tendo em vista que o trabalho de parto poderia iniciar a qualquer momento, e o médico, depois de ser questionado pela recepcionista (Raquel - somente no final do enredo o nome da recepcionista é revelado) a respeito da condição de Milena e de Miguel, recomenda-lhe respeitar a vida das pessoas da mesma maneira como gostaria que os outros respeitassem a sua vida. Um importante questionamento que se pode fazer é a respeito do comportamento de Raquel: ela teria agido dessa maneira com Milena por desconhecimento ou por crueldade? Considerando as pistas que o narrador fornece, como o fato de a recepcionista demonstrar ironia quando questiona Milena a respeito do pai da criança, inclino-me à segunda alternativa. A falta de sensibilidade e de empatia da recepcionista em relação ao casal trans também são habilmente percebidas pelo médico, que, elegantemente, indica-lhe olhar para os outros como gostaria que olhassem para si. 
Como se pôde observar a partir das reflexões e dos exemplos, a escrita de Atena Beauvoir, além de se constituir como uma narrativa de afirmação da existência (transgênero) e da resistência (respeito à condição transgênero), está voltada para dar visibilidade ao que, aos olhos de uma sociedade falocêntrica heteronormativa transfóbica, deve se manter invisível nas zonas abissais e sem qualquer possibilidade de representação. $O$ texto dessa autora soa como um manifesto das vozes silenciadas por, desde sempre, terem de construir as noções de homem e de mulher apenas pela genitália que seus corpos possuem. Essas noções podem e devem ser ampliadas para a existência que cada um reconhece em si, para além da condição fenotípica que cada ser humano possui. É preciso aceitar que "a distinção entre masculino e feminino é tão engessada, tão esmagadora. (...) nossa aparência e as coisas que fazem parte disso inclusive a sexualidade - precisam ser mais fluidas" (DESPENTES, 2016, p. 15).

Por fim, aspectos intrínsecos à condição humana, como: o amor e o desejo pelo outro, a carência de afeto oriunda do sentimento de rejeição, os sentimentos de abandono e de solidão e a consciência do vazio existencial, por exemplo, estão presentes do início ao fim no conjunto de narrativas de Contos Transantopológicos. Esses sentimentos, entretanto, por se referirem a personagens permanentemente invisibilizadas e localizadas socialmente à margem, a meu ver, parecem potencialmente mais latentes, mais doloridos, mais contundentes. Por isso, também, é importante e legítimo problematizar e garantir que as sexualidades "fora da normalidade" possam contestar e questionar discursos hegemônicos transfóbicos, assegurando representatividade trans na literatura. E é exatamente isso que Atena Beauvoir faz ao escrever e publicar Contos Transantropológicos.

Se é verdade que, muitas vezes, a vida imita a arte, acredito ser o caso de considerar a possibilidade de a realidade espelhar-se na ficção. Se os discursos hegemônicos são contestados e, algumas vezes, rompidos no âmbito da literatura, garantindo vez e voz às pessoas transgênero, tal ruptura e garantia, mesmo que utopicamente, poderia e deveria ser estendida ao plano da realidade.

\section{REFERÊNCIAS}

ANGRIMANI, Danilo. Nicola - um romance transgênero. São Paulo: Summus, 1999.

BEAUVOIR, Atena. Contos transantropológicos. Porto Alegre: Taverna, 2018.

BEAUVOIR, Simone de. O segundo sexo: a experiência vivida. Tradução de Sérgio Milliet. 2. ed. São Paulo: Difusão Europeia do Livro, 1967.

BUTLER, Judith. Problemas de gênero: feminismo e subversão da identidade. Tradução de Renato Aguiar. Rio de Janeiro: Civilização Brasileira, 2017.

DESPENTES, Virginie. Teoria King Kong. Tradução Márcia Bechara. São Paulo: n-1, 2016.

RESENDE, Marcelo Branquinho Massucatto. De Orlando a Orlanda: performances trans na literatura do século $X X$. Dissertação (Mestrado em Letras). Faculdade de Ciências e Letras de Araraquara, Universidade Estadual Paulista "Júlio de Mesquita Filho". São Paulo, 2019, p. 106. Disponível em: https://repositorio.unesp.br/ bitstream/handle/11449/180962/resende_mbm_me_arafcl.pdf?sequence=5\&isAllowed=y. Acesso em: 10 maio 2021. 